\title{
Temperaturas e substratos para germinação e vigor de sementes de Euterpe oleracea Mart. ${ }^{1}$
}

\author{
Temperatures and substrates for germination and vigor of Euterpe oleracea Mart. \\ Seeds
}

\author{
Juliana Simões Nobre Gama ${ }^{2 *}$, Denise Maria de Oliveira Monte ${ }^{3}$, Edna Ursulino Alves ${ }^{4}$, Riselane de Lucena \\ Alcântara Bruno ${ }^{4}$ e Joel Martins Braga Júnior ${ }^{2}$
}

\begin{abstract}
Resumo - O conhecimento das condições ótimas para a germinação, principalmente da temperatura e do substrato, é de fundamental importância, tendo em vista que estes fatores variam entre sementes de diferentes espécies. O objetivo do trabalho foi avaliar a influência de diferentes substratos e temperaturas para condução de testes de germinação e vigor de sementes de Euterpe oleracea. A pesquisa foi realizada no Laboratório de Análise de Sementes do Centro de Ciências Agrárias da Universidade Federal da Paraíba. Os tratamentos foram distribuídos em esquema fatorial 4 x 4, com os fatores temperaturas $\left(20-30 ; 25 ; 30\right.$ e $\left.35^{\circ} \mathrm{C}\right)$ e substratos (areia, Bioplant ${ }^{\mathbb{R}}$, Plantmax ${ }^{\circledR}$ e vermiculita) e quatro repetições cada. Para avaliação do efeito dos tratamentos foram realizados testes de germinação e vigor (índice de velocidade de germinação, comprimento e massa seca de plântulas). As condições ideais para testes de germinação e vigor em sementes de Euterpe oleracea estão em substrato vermiculita sob temperaturas de $20-30 ; 30$ e $35^{\circ} \mathrm{C}$, areia a 30 e $35^{\circ} \mathrm{C}$, plantmax ${ }^{\circledR}$ a $20-30{ }^{\circ} \mathrm{C}$ e bioplant ${ }^{\circledR}$ a $35^{\circ} \mathrm{C}$.
\end{abstract}

Palavras-chave - Açaizeiro. Florestal. Semente recalcitrante. Amazônia.

\begin{abstract}
The objective of this study was to evaluate the influence of different substrates and temperatures for conducting tests of seed germination and vigor in Euterpe oleracea. The work was realized at the Seed Analysis Laboratory of (CCA-UFPB). The treatments were distributed in a factorial $4 \times 4$, four temperatures $\left(20-30 ; 25 ; 30\right.$ and $\left.35{ }^{\circ} \mathrm{C}\right)$ and four substrates (sand, Bioplant ${ }^{\circledR}$, Plantmax ${ }^{\circledR}$ and vermiculite), used four replications each. Were evaluated the following characteristics: germination (\%), germination speed index, length and dry mass of seedlings. The ideal conditions for testing the germination and vigor in Euterpe oleracea seeds are in vermiculite under temperatures of $20-30 ; 30$ and $35^{\circ} \mathrm{C}$, sand to 30 and $35^{\circ} \mathrm{C}$, plantmax ${ }^{\circledR} 20-30{ }^{\circ} \mathrm{C}$ and bioplant ${ }^{\circledR} 35^{\circ} \mathrm{C}$.
\end{abstract}

Key words - Açaizeiro. Forest. Recalcitrant seed. Amazon.

\footnotetext{
* Autor para correspondência

${ }^{1}$ Recebido para publicação em 06/05/2010; aprovado em 13/11/2010

Trabalho de Monografia apresentado ao Curso de Graduação em Agronomia da Universidade Federal de Paraíba

${ }^{2}$ Programa de Pós-Graduação em Agronomia, CCA/UFPB, Caixa Postal 66, Areia-PB, Brasil, 58.397-000, juliananobrecca@hotmail.com, joelbraga@hotmail.com

${ }^{3}$ Programa de Pós-Graduação em Produção Agrícola, UAG/UFRPE, Garanhuns-PE, Brasil, mozart20e3@hotmail.com

${ }^{4}$ Departamento de Fitotecnia e Ciências Ambientais, CCA/UFPB, Areia-PB, Brasil, ednaursulino@cca.ufpb.br, riselane@pq.cnpq.br
} 


\section{Introdução}

O açaizeiro (Euterpe oleracea Mart.) é uma espécie nativa da Amazônia brasileira, sendo o Estado do Pará o principal centro de dispersão natural dessa palmácea, podendo ser encontradas populações espontâneas nos Estados do Amapá, Maranhão, Mato Grosso, Tocantins e em países da América do Sul e da América Central (EMBRAPA, 2008). A espécie pertence à família Arecaceae, que engloba aproximadamente 200 gêneros e cerca de 2.600 espécies, com distribuição predominantemente tropical e subtropical (JONES, 1995).

Esta espécie se destaca entre os diversos recursos vegetais devido a sua abundância e também pelo fato de ser a principal fonte de matéria-prima para a agroindústria do palmito (EMBRAPA, 2008). Dos frutos são extraídos o vinho e a polpa que é habitualmente consumida in natura, bastante utilizada na fabricação de sorvetes, licores, doces e geléias, podendo ser aproveitada, também, para a extração de corantes e antocianina (TINOCO, 2005).

Embora a propagação assexuada possa ser utilizada, a multiplicação do açaizeiro é realizada, prioritariamente, por unidades de dispersão, tecnologicamente denominadas sementes, que inclui o endocarpo e o mesocarpo, os quais representam $73 \%$ da massa do fruto. Cada planta é capaz de produzir mais de 6.000 unidades por safra, com germinação inicial próxima a 90\% (OLIVEIRA et al., 2000).

O conhecimento das condições ótimas para a germinação, principalmente da temperatura e do substrato, é de fundamental importância, pois estes fatores variam entre sementes de diferentes espécies (ALBUQUERQUE et al., 1998). Para as espécies florestais brasileiras, a temperatura ótima de germinação situa-se entre 15 e $30^{\circ} \mathrm{C}$, a qual está normalmente relacionada às temperaturas da região de origem da espécie, na época favorável para a germinação (ANDRADE et al., 2000). Dessa forma, existem sementes de espécies cujo processo germinativo é favorecido por temperaturas constantes (MATHEUS; LOPES, 2009), alternadas (LOPES e SOARES, 2003) e por um intervalo amplo de temperatura (SILVA et al., 2002).

Em alguns estudos, houve a definição de temperaturas ideais para testes de germinação e vigor em sementes de palmeiras, a exemplo das temperaturas $25{ }^{\circ} \mathrm{C}$ para Phoenix roebelenii $\mathrm{O}^{\prime}$ Brien, $35{ }^{\circ} \mathrm{C}$ para Thrinax parviflora Swartz. (PIVETTA et al., 2005) e $30{ }^{\circ} \mathrm{C}$ para Archontophoenix cunninghamii Wendl. e Drude (PIVETTA et al., 2008).

O substrato influencia diretamente a germinação, uma vez que em função de sua capacidade de retenção de água, da sua estrutura e aeração interfere no fornecimento de água e de oxigênio para as sementes e serve de suporte físico para o desenvolvimento da plântula (FIGLIOLIA et al., 1993). Vários resultados sobre substratos que proporcionam maior porcentagem de germinação são encontrados em diferentes espécies, como areia e vermiculita para sementes de palmeiras Oenocarpus minor Mart. (SILVA et al., 2006), areia e pó de côco para Apeiba tibourbou Aubl (PACHECO et al., 2007).

A interação significativa entre temperatura e substrato pode proporcionar diferentes respostas, até para sementes submetidas à mesma temperatura, devido às diferenças na capacidade de retenção de água e na quantidade de luz que o substrato permite chegar à semente (FIGLIOLIA et al., 1993).

Diante da importância econômica da espécie Euterpe oleracea, objetivou-se avaliar o efeito de diferentes substratos e temperaturas na germinação e vigor de suas sementes.

\section{Material e métodos}

O experimento foi realizado no Laboratório de Análise de Sementes (LAS) pertencente ao Departamento de Fitotecnia e Ciências Ambientais do Centro de Ciências Agrárias da Universidade Federal da Paraíba (CCA-UFPB), em Areia - PB. Os frutos de Euterpe oleracea Mart. foram colhidos de matrizes localizadas no município de Tracuateua - PA. Após a colheita os frutos foram embalados em jornal e mantidos dentro de sacos plásticos por aproximadamente 10 dias, período em que foram transportados para o LAS.

No beneficiamento, os frutos foram lavados com hipoclorito de sódio na proporção de 1:1, em seguida foram retirados manualmente o epicarpo, o mesocarpo e as fibras e posteriormente foi determinado o teor de água (BRASIL, 2009), utilizando-se quatro repetições de 10 sementes.

As sementes foram semeadas $2 \mathrm{~cm}$ deprofundidade, em bandejas plásticas contendo os substratos areia lavada, previamente peneirada e esterilizada em autoclave e os

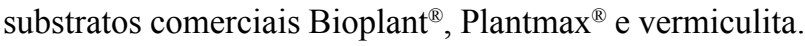
A manutenção da umidade foi realizada por meio de regas diárias. $\mathrm{O}$ experimento foi conduzido em câmaras de germinação do tipo $\mathrm{BOD}$, reguladas nas temperaturas constantes de $25 ; 30$ e $35{ }^{\circ} \mathrm{C}$, bem como na temperatura alternada $20-30{ }^{\circ} \mathrm{C}$, sob luz branca, nos regimes de 8 horas com luz e 16 horas no escuro. Para avaliar a influência dos tratamentos foram realizados os seguintes testes:

Porcentagem de germinação: foram utilizadas 100 sementes por tratamento, divididas em quatro repetições de 25 sementes, cujas contagens do número de sementes germinadas foram realizadas dos 19 aos 44 dias após a instalação do teste, utilizando-se como critério de avaliação o epicótilo acima do substrato. 
Índice de velocidade de germinação: foram realizadas contagens diárias das plântulas normais durante 44 dias e o índice foi calculado conforme a fórmula proposta por Maguire (1962).

Comprimento e massa seca de plântulas: aos 44 dias após a semeadura, as plântulas foram retiradas das bandejas, lavadas e medidas da raiz primária à parte aérea, com o auxílio de uma régua graduada em centímetros, calculando-se o comprimento médio por plântula em cada repetição. Depois de medidas, as plântulas foram colocadas para secar em estufa com circulação de ar forçada, regulada a $65{ }^{\circ} \mathrm{C}$ até atingir peso constante (48 horas). Após esse período as amostras foram colocadas para esfriar em dessecador e, em seguida, pesadas em balança analítica com precisão de $0,0001 \mathrm{~g}$, conforme recomendações de Nakagawa (1999). Os resultados foram expressos em g/plântula.

O delineamento experimental utilizado foi inteiramente ao acaso, com os tratamentos distribuídos em esquema fatorial $4 \times 4$, sendo os fatores temperaturas $\left(20-30 ; 25 ; 30\right.$ e $\left.35{ }^{\circ} \mathrm{C}\right)$ e substratos (areia, Bioplant ${ }^{\circledR}$, Plantmax ${ }^{\circledR}$ e vermiculita), utilizando-se quatro repetições cada. Para os dados de temperatura foi aplicado o contraste (20-30 vs 25 e $30^{\circ} \mathrm{C}$ ). Os dados obtidos foram submetidos à análise de variância utilizando-se o teste $\mathrm{F}$ e as médias comparadas pelo teste Tukey a $1 \%$ de probabilidade.

\section{Resultados e discussão}

De acordo com a Tabela 1, observa-se que para sementes de Euterpe oleracea, a análise de variância das variáveis germinação, índice de velocidade de germinação, comprimento e massa seca de plântulas diferiram significativamente para os diferentes substratos e temperaturas, a $1 \%$ de probabilidade pelo teste $\mathrm{F}$.
Pelos dados da porcentagem de germinação de sementes de Euterpe oleracea, cujo teor de água inicial foi de $38 \%$, observou-se que as porcentagens de germinação das sementes submetidas à temperatura de $20-30{ }^{\circ} \mathrm{C}$ foram mais elevadas quando utilizou-se os substratos Bioplant ${ }^{\circledR}$, Plantmax ${ }^{\circledR}$ e vermiculita. Já o substrato areia proporcionou as maiores porcentagens de germinação sob a temperatura de $30{ }^{\circ} \mathrm{C}$, não diferindo estatisticamente dos substratos Plantmax ${ }^{\circledR}$ e vermiculita. Com o aumento da temperatura para $35{ }^{\circ} \mathrm{C}$ todos os substratos utilizados apresentaram praticamente a mesma porcentagem de germinação (TAB. 2). Na temperatura de $25^{\circ} \mathrm{C}$ os substratos areia e vermiculita se sobressaíram aos demais substratos, apresentando os maiores valores de porcentagem de germinação. Pode-se observar, também, ao se comparar as temperaturas, que a de $25{ }^{\circ} \mathrm{C}$ foi a menos favorável à germinação desta espécie. Os resultados indicam que temperaturas amenas não são satisfatórias à germinação, provavelmente pelo fato das mesmas serem originadas de regiões com temperaturas elevadas.

O intervalo de temperatura de 30 a $35{ }^{\circ} \mathrm{C}$ foi indicado por Broschat (1994) como o mais favorável para germinação de sementes de várias espécies de palmeiras. Entretanto, Lorenzi et al. (1996) recomendaram a faixa de temperatura entre 24 e $28^{\circ} \mathrm{C}$.

$\mathrm{Na}$ estimativa do contraste (TAB. 2) podese observar um decréscimo de $5 \%$ na germinação das sementes de Euterpe oleracea submetidas à temperatura alternada de $20-30{ }^{\circ} \mathrm{C}$, no substrato areia, quando comparada com as temperaturas constantes de 25 e $30{ }^{\circ} \mathrm{C}$. Para os substratos Bioplant ${ }^{\circledR}$, Plantmax ${ }^{\circledR}$ e vermiculita ocorreu o inverso, a temperatura de 20 $30{ }^{\circ} \mathrm{C}$ proporcionou um aumento de 34,$8 ; 9,5$ e 6,0 $\%$, respectivamente, na porcentagem de germinação quando comparada as temperaturas de 25 e $30{ }^{\circ} \mathrm{C}$.

Tabela 1 - Resumo da análise de variância das características (germinação - G; índice de velocidade de geminação - IVG; comprimento de plântulas - CP e massa seca de plântulas - MSP) avaliadas em sementes de Euterpe oleracea Mart., em função de substratos (S) e temperaturas $(\mathrm{T})$

\begin{tabular}{cccccc}
\hline \multirow{2}{*}{ FV } & GL & \multicolumn{4}{c}{ Quadrado médio } \\
\cline { 3 - 6 } & & G & IVG & CP & MSP \\
\hline S & 3 & $1812,14^{* *}$ & $1,938^{* *}$ & $142,10^{* *}$ & $0,00405^{* *}$ \\
T & 3 & $704,47^{* *}$ & $0,165^{* *}$ & $15,61^{* *}$ & $0,00069^{* *}$ \\
S x T & 9 & $463,08^{* *}$ & $0,023^{* *}$ & $3,03^{* *}$ & $0,00009^{* *}$ \\
Erro & 48 & 17,72 & 0,003 & 0,27 & 0,00001 \\
C.V (\%) & & 4,82 & 6,62 & 5,80 & 4,65 \\
\hline
\end{tabular}

** Significativo a $1,0 \%$ de probabilidade pelo teste $\mathrm{F}$ 
Tabela 2 - Germinação (\%) de sementes de Euterpe oleracea Mart. em função de substratos e temperaturas

\begin{tabular}{|c|c|c|c|c|c|}
\hline \multirow{2}{*}{ Substratos } & \multicolumn{4}{|c|}{ Temperaturas $\left({ }^{\circ} \mathrm{C}\right)$} & \multirow{2}{*}{ Contraste $20-30$ vs 25 e $30\left({ }^{\circ} \mathrm{C}\right)$} \\
\hline & $20-30$ & 25 & 30 & 35 & \\
\hline Areia & $85 \mathrm{~b}$ & $83 \mathrm{a}$ & $97 \mathrm{a}$ & $92 \mathrm{a}$ & $-5,0 *$ \\
\hline Bioplant ${ }^{\circledR}$ & $96 \mathrm{a}$ & $41 \mathrm{c}$ & $81 \mathrm{~b}$ & $92 \mathrm{a}$ & $34,8 * *$ \\
\hline Plantmax ${ }^{\circledR}$ & $95 \mathrm{a}$ & $74 \mathrm{~b}$ & $97 \mathrm{a}$ & $91 \mathrm{a}$ & $9,5 * *$ \\
\hline Vermiculita & $96 a$ & $87 \mathrm{a}$ & $93 \mathrm{a}$ & $95 \mathrm{a}$ & $6,0 *$ \\
\hline DMS & D & 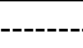 & --- & ----" & \\
\hline
\end{tabular}

Médias seguidas de mesma letra na coluna, não diferem estatisticamente entre si, pelo teste Tukey a $1 \%$ de probabilidade

Diferentes resultados foram obtidos em sementes de palmeiras Euterpe edulis Mart. (ANDRADE et al., 1999), Phoenix roebelenii (IOSSI et al., 2003), Oenocarpus minor Mart. (SILVA et al., 2006) e Archontophoenix cunninghamii H. Wendl. e Drude (PIVETTA et al., 2008), os quais não apresentaram interação significativa entre os substratos e as temperaturas com relação a porcentagem de germinação destas espécies.

Os dados referentes ao índice de velocidade de germinação de sementes de Euterpe oleraceae submetidas a diferentes substratos e temperaturas encontram-se na Tabela 3. Verificou-se que os maiores índices foram obtidos nos substratos Plantmax ${ }^{\circledR} \mathrm{e}$ vermiculita, na temperatura alternada de 20-30 ${ }^{\circ} \mathrm{C}$. Quando se utilizou a temperatura de $30^{\circ} \mathrm{C}$, os substratos vermiculita e areia não apresentaram diferença entre si e foram os substratos que resultaram no maior número de sementes germinadas. A temperatura de $35{ }^{\circ} \mathrm{C}$ não interferiu no índice de velocidade de germinação de sementes de Euterpe oleraceae nos diferentes substratos. Dessa forma, essa temperatura não foi capaz de evidenciar o melhor substrato a ser utilizado. Mais uma vez constatou-se que a temperatura de $25{ }^{\circ} \mathrm{C}$ não favorece as sementes de Euterpe oleraceae.
De acordo com o efeito real do contraste (TAB. 3) verifica-se que a temperatura alternada de $20-30{ }^{\circ} \mathrm{C}$ proporcionou um aumento significativo no índice de velocidade de germinação de sementes de Euterpe oleracea em todos os substratos avaliados, quando comparada com as temperaturas constantes de 25 e $30^{\circ} \mathrm{C}$.

O índice de velocidade de germinação em sementes da palmeira Dypsis decaryi foi reduzido na temperatura de $35{ }^{\circ} \mathrm{C}$ (LUZ et al., 2008), além de não ter ocorrido efeito dos substratos avaliados (areia e vermiculita). Para Euterpe edulis, os fatores isolados temperaturas de 20-30 e $25^{\circ} \mathrm{C}$ em vermiculita proporcionaram os maiores índices de velocidade de germinação (ANDRADE et al., 1999). As sementes de Phoenix roebelenii expressaram maior índice de velocidade de germinação nos substratos esfagno e areia, na temperatura de $30^{\circ} \mathrm{C}$ (IOSSI et al., 2003). Em relação à Archontophoenix cunninghamii o índice de velocidade de germinação foi maior quando se utilizou, isoladamente, as temperaturas de 25 e $30^{\circ} \mathrm{C}$ e o substrato vermiculita (PIVETTA et al., 2008). Ainda com relação às sementes de palmeiras, Pivetta et al. (2005) relataram que as sementes de Thrinax parviflora expressaram maior índice de velocidade de germinação em uma ampla faixa de temperaturas $\left(25 ; 30 ; 35 ; 20-30\right.$ e $\left.25-35^{\circ} \mathrm{C}\right)$.

Tabela 3 - Índice de velocidade de germinação (IVG) de sementes de Euterpe oleracea Mart. em função de substratos e temperaturas

\begin{tabular}{|c|c|c|c|c|c|}
\hline \multirow{2}{*}{ Substratos } & \multicolumn{4}{|c|}{ Temperaturas $\left({ }^{\circ} \mathrm{C}\right)$} & \multirow{2}{*}{ Contraste $20-30$ vs 25 e $30\left({ }^{\circ} \mathrm{C}\right)$} \\
\hline & $20-30$ & 25 & 30 & 35 & \\
\hline Areia & $1,04 \mathrm{~b}$ & $0,48 \mathrm{ab}$ & $1,12 \mathrm{ab}$ & $1,52 \mathrm{a}$ & $0,23 * *$ \\
\hline Bioplant ${ }^{\circledR}$ & $1,04 \mathrm{~b}$ & $0,23 \mathrm{c}$ & $0,91 \mathrm{c}$ & $1,13 \mathrm{a}$ & $0,47 * *$ \\
\hline Plantmax ${ }^{\circledR}$ & $1,21 \mathrm{a}$ & $0,43 \mathrm{~b}$ & $1,07 \mathrm{~b}$ & $1,09 \mathrm{a}$ & $0,45 * *$ \\
\hline Vermiculita & $1,31 \mathrm{a}$ & $0,58 \mathrm{a}$ & $1,24 \mathrm{a}$ & $1,19 \mathrm{a}$ & $0,39 * *$ \\
\hline
\end{tabular}

Médias seguidas de mesma letra na coluna, não diferem estatisticamente entre si, pelo teste de Tukey a 1\% de probabilidade 
As médias de comprimento das plântulas de Euterpe oleracea em função de temperaturas e substratos estão presentes na Tabela 4. Observou-se que os maiores valores foram obtidos nos substratos Plantmax ${ }^{\circledR}$ e vermiculita, nas temperaturas de $20-30$ e $30{ }^{\circ} \mathrm{C}$, e na vermiculita a 25 e $35^{\circ} \mathrm{C}$. Para o desenvolvimento inicial das plântulas de E. oleracea as exigências também são semelhantes àquelas requeridas no processo germinativo, fato este que limita as condições de sobrevivência da referida espécie.

Em sementes de Phoenix roebelenii, constatouse maior comprimento da raiz primária de plântulas nos substratos areia e vermiculita, enquanto para a parte aérea foi no substrato esfagno (IOSSI et al., 2003). Para outras espécies florestais, a exemplo de Crataeva tapia L., o maior comprimento da raiz primária e parte aérea de plântulas foram obtidos em substrato rolo de papel (GONÇALVES et al., 2007).

$\mathrm{Na}$ estimativa do contraste (TAB. 4) pode-se observar, mais uma vez, que a temperatura alternada de 20-30 ${ }^{\circ} \mathrm{C}$ proporcionou um aumento significativo no comprimento de plântulas de Euterpe oleracea em todos os substratos, quando comparada as temperaturas constantes de 25 e $30{ }^{\circ} \mathrm{C}$. Nos substratos areia, Bioplant $^{\circledR}$, Plantmax ${ }^{\circledR}$ e vermiculita o aumento foi de 1,$78 ; 3,78 ; 4,03$ e $3,97 \mathrm{~cm}$, respectivamente.

Os dados de massa seca das plântulas de Euterpe oleraceae encontram-se na Tabela 5. Constatou-se que os maiores valores foram obtidos nos substratos vermiculita a $20-30{ }^{\circ} \mathrm{C}$, areia e Plantmax ${ }^{\circledR}$ a $30{ }^{\circ} \mathrm{C}$ e em vermiculita a $35{ }^{\circ} \mathrm{C}$. As condições citadas proporcionaram melhor crescimento das plântulas e, consequentemente, maior acúmulo de fitomassa em suas estruturas. A determinação da massa seca de plântulas é uma maneira de avaliar o seu crescimento, conseguindose determinar, com precisão, a transferência de reservas da semente para o eixo embrionário (NAKAGAWA, 1999), de forma que as amostras com maior massa seca são consideradas de maior vigor.

Diferentes resultados foram obtidos em Phoenix roebelenii, sendo os substratos vermiculita e areia responsáveis pelos menores valores de massa seca

Tabela 4 - Comprimento de plântulas de Euterpe oleracea Mart. em função de substratos e temperaturas

\begin{tabular}{|c|c|c|c|c|c|}
\hline \multirow{2}{*}{ Substratos } & \multicolumn{4}{|c|}{ Temperaturas $\left({ }^{\circ} \mathrm{C}\right)$} & \multirow{2}{*}{ Contraste $20-30$ vs 25 e $30\left({ }^{\circ} \mathrm{C}\right)$} \\
\hline & $20-30$ & 25 & 30 & 35 & \\
\hline Areia & $9,07 \mathrm{c}$ & $4,84 \mathrm{~b}$ & $9,73 \mathrm{~b}$ & $9,95 \mathrm{~b}$ & $1,78 * *$ \\
\hline Bioplant ${ }^{\circledR}$ & $10,27 \mathrm{~b}$ & $3,99 \mathrm{~b}$ & $8,97 \mathrm{~b}$ & $9,90 \mathrm{~b}$ & $3,78 * *$ \\
\hline Plantmax ${ }^{\circledR}$ & $11,76 \mathrm{a}$ & $4,30 \mathrm{ab}$ & $11,15 \mathrm{a}$ & $9,30 \mathrm{~b}$ & $4,03 * *$ \\
\hline Vermiculita & $12,32 \mathrm{a}$ & $5,28 \mathrm{a}$ & $11,42 \mathrm{a}$ & $12,71 \mathrm{a}$ & $3,97 * *$ \\
\hline DMS & ------------ & ------. & ------- & ----------- & \\
\hline
\end{tabular}

Médias seguidas de mesma letra na coluna, não diferem estatisticamente entre si, pelo teste de Tukey a 1\% de probabilidade

Tabela 5 - Massa seca de plântulas de Euterpe oleracea Mart. em função de substratos e temperaturas

\begin{tabular}{|c|c|c|c|c|c|}
\hline \multirow{2}{*}{ Substratos } & \multicolumn{4}{|c|}{ Temperaturas $\left({ }^{\circ} \mathrm{C}\right)$} & \multirow{2}{*}{ Contraste $20-30$ vs 25 e $30\left({ }^{\circ} \mathrm{C}\right)$} \\
\hline & $20-30$ & 25 & 30 & 35 & \\
\hline Areia & $0,0665 \mathrm{~b}$ & $0,0375 \mathrm{a}$ & $0,0688 \mathrm{a}$ & $0,0645 \mathrm{~b}$ & $0,013 * *$ \\
\hline Bioplant ${ }^{\circledR}$ & $0,0573 \mathrm{c}$ & $0,0303 \mathrm{~b}$ & $0,0525 \mathrm{~b}$ & $0,0623 \mathrm{~b}$ & $0,015 * *$ \\
\hline Plantmax ${ }^{\circledR}$ & $0,0658 \mathrm{~b}$ & $0,0313 \mathrm{~b}$ & $0,0663 \mathrm{a}$ & $0,0598 \mathrm{~b}$ & $0,017 * *$ \\
\hline Vermiculita & $0,0783 \mathrm{a}$ & $0,0378 \mathrm{a}$ & $0,0685 \mathrm{a}$ & $0,0805 \mathrm{a}$ & $0,025 * *$ \\
\hline DMS & 0,005 & & & & \\
\hline
\end{tabular}

Médias seguidas de mesma letra na coluna, não diferem estatisticamente entre si, pelo teste de Tukey a $1 \%$ de probabilidade 
(IOSSI et al., 2003). Em estudos realizados, Alves et al. (2002) obtiveram melhores valores de massa seca de plântulas de Mimosa caesalpiniaefolia Benth. sob temperatura de $25^{\circ} \mathrm{C}$ em substratos entre areia e vermiculita e, ainda, em substrato areia a $30{ }^{\circ} \mathrm{C}$. Para Bauhinia divaricata L., Alves et al. (2008) obtiveram melhores resultados nos substratos areia e vermiculita sob temperatura constante de $30{ }^{\circ} \mathrm{C}$.

Para massa seca de plântulas de Euterpe oleracea o efeito real do contraste enfatiza, mais uma vez, que a temperatura alternada de $20-30{ }^{\circ} \mathrm{C}$ em relação às temperaturas constantes de 25 e $30^{\circ} \mathrm{C}$ proporcionou um aumento significativo de 0,$013 ; 0,015 ; 0,017$ e 0,025 (g/plântula), nos substratos areia, Bioplant ${ }^{\circledR}$, Plantmax $^{\circledR}$ e vermiculita, respectivamente (TAB. 5).

\section{Conclusão}

As condições ideais para testes de germinação e vigor em sementes de Euterpe oleracea Mart. são nos substratos vermiculita, sob temperaturas de 20-30; 30 e $35^{\circ} \mathrm{C}$, areia a 30 e $35^{\circ} \mathrm{C}$, Bioplant ${ }^{\circledR}$ a $35^{\circ} \mathrm{C}$ e Plantmax ${ }^{\circledR}$ a $20-30{ }^{\circ} \mathrm{C}$.

\section{Referências}

ALBUQUERQUE, M. C. F. et al. Influência da temperatura e do substrato na germinação de sementes de saguaraji (Colubrina glandulosa Perk. - Rhamnaceae). Revista Brasileira de Sementes, v. 20, n. 02, p. 108-111, 1998.

ALVES, E. U. et al. Germinação e vigor de sementes de Bauhinia divaricata L. Ciência Rural, v. 38, n. 04, p. 960-966, 2008.

ALVES, E. U. et al. Germinação de sementes de Mimosa caesalpiniaefolia Benth. em diferentes substratos e temperaturas. Revista Brasileira de Sementes, v. 24, n. 01, p. 169-178, 2002.

ANDRADE, A. C. S. et al. Germinação de sementes de jenipapo: temperatura, substrato e morfologia do desenvolvimento pós-seminal. Pesquisa Agropecuária Brasileira, v. 35, n. 03, p. 609-615, 2000.

ANDRADE, A. C. S. et al. Reavaliação do efeito do substrato e da temperatura na germinação de sementes de palmiteiro (Euterpe edulis Mart.). Revista Árvore, v. 23, n. 03, p. 279-283, 1999.

BRASIL. Ministério da Agricultura e reforma Agrária. Regras para análise de sementes. Brasília-DF: Departamento Nacional de Produção Vegetal - SNA/DNPV/CLAV, 2009. 399 p.

BROSCHAT, T. K. Palm seed propagation. Acta Horticulturae, n. 360, p. 141-147, 1994.
EMPRESA BRASILEIRA DE PESQUISA AGROPECUÁRIA (EMBRAPA). Sistema de Produção do Açaí. Disponível em: $<$ http://sistemasdeproducao.cnptia.embrapa.br/ FontesHTML/ Acai/SistemaProducaoAcai_2ed/index.htm $>$ Acesso em: 15 set. 2008 .

FIGLIOLIA, M. B. OLIVEIRA, E. C.; PIÑA-RODRIGUES, F. C. M. Análise de sementes. In: AGUIAR, I. B.; PIÑARODRIGUES, F. C. M; FIGLIOLIA, M. B. Sementes Florestais Tropicais. Brasília: ABRATES, 1993. p. 137-174.

GONÇALVES, E. P. et al. Germinação e vigor de sementes de Crataeva tapia L. em diferentes substratos. Acta Scientiarum Biological Science, v. 29, n. 04, p. 363-367, 2007.

IOSSI, E. et al. Efeitos de substratos e temperaturas na germinação de sementes de tamareira-anã (Phoenix roebelenii O'Brien). Revista Brasileira de Sementes, v. 25, n. 02, p. 63-69, 2003.

JONES, D. L. Palms: throughout the word. Washington: Smithsonian Institution, 1995. $410 \mathrm{p}$.

LOPES, J. C.; SOARES, A. S. Germinação de sementes de Miconia cinnamomifolia (Dc.) Naud. Brasil Florestal, n. 75, p. 31-38, 2003.

LORENZI, H.; SOUZA, H. M.; MEDEIROS, J. T. Palmeiras no Brasil: nativas e exóticas. Nova Odessa: Plantarum, 1996. 303 p.

LUZ, P. B. et al. Germinação de sementes de Dypsis decaryi (Jum.) Beentje \& J. Dransf. (Arecaceae). Ciência e Agrotecnologia, v. 32, n. 05, p. 1461-1466, 2008.

MAGUIRE, J. D. Speed of germination aid in selection and evaluation for seedling emergence and vigor. Crop Science, v. 02, n. 02, p. 176-177, 1962.

MATHEUS, M. T.; LOPES, J. C. Temperaturas cardinais para a germinação de sementes de Erythrina variegata L. Revista Brasileira de Sementes, v. 31, n. 03, p. 115-122, 2009.

NAKAGAWA, J. Testes de vigor baseados no desempenho das plântulas. In: KRZYZANOWSKI, F. C.; VIEIRA, R. D.; FRANÇA NETO, J. B. Vigor de sementes: conceitos e testes. Londrina: ABRATES, 1999. p. 2.1-2.24.

OLIVEIRA, M. S. P.; CARVALHO, J. E. U.; NASCIMENTO, W. M. O. Açaí (Euterpe oleracea Mart.). Jaboticabal: Funep, 2000. 52 p. (Série frutas nativas, 7).

PACHECO, M. V. et al. Germinação de sementes de Apeiba tibourbou Aubl. em função de diferentes substratos e temperaturas. Scientia Forestalis, n. 73, p. 19-25, 2007.

PIVETTA, K. F. L. et al. Tamanho do diásporo, substrato e temperatura na germinação de sementes de Archontophoenix cunninghamii (Arecaceae). Revista de Biologia e Ciências da Terra, v. 08, n. 01, p. 126-134, 2008.

PIVETTA, K. F. L. et al. Efeito da temperatura e do armazenamento na germinação de sementes de Thrinax parviflora Swartz. (Arecaceae). Científica, v. 33, n. 02, p. 178-184, 2005. 
SILVA, B. M. S. et al. Germinação de sementes e emergência de plântulas de Oenocarpus minor Mart. (Arecaceae). Revista Brasileira de Fruticultura, v. 28, n. 02, p. 289-292, 2006.

SILVA, L. M. M.; RODRIGUES, T. J. D.; AGUiAR, I. B. Efeito da luz e da temperatura na germinação de sementes de aroeira (Myracrodruon urundeuva Allemão). Revista Árvore, v. 26, n. 06, p. 691-697, 2002.

TINOCO, A. C. Açaí amazônico: novas perspectivas de negócio. Belém, PA: Embrapa Amazônia Oriental, 2005. 